\section{Russell and recent psychology}

In considering Russell's interest in psychology usually one thinks of The Analysis of Mind, his transatlantic exchanges with William James, or such cormon-sense guides to everyday 1 ife as the Conquest of Happiness. One does not think of his painful concern over the paradoxes and his theory of logical types. Oddly enough, however, it may emerge that his most important influence on psychology will stem from this area of his thought.

To elaborate upon this claim I should like to sketch the psychological terrain wherein logical concepts introduced or developed by Russell have been acknowledged as having decided value. I shall then present a partial bibliography, with commentary, to indicate some of the surprising places where Russell's name has been turning up.

In 1956 researchers associated with Stanford University and the Veterans Administration Hospital in Palo Alto published a seminal paper entitled "Toward a Theory of Schizophrenia". This paper heralded a cormunicational approach not only to schizophrenia, but to emotional disorders in general. The authors acknowledge their debt to Russell as follows:

Our approach is based on that part of communications theory which Russell has called the Theory of Logical Types. The central thes is of this theory is that there is a discontinuity between a class and its members. The class cannot be a member of itself nor can one of the members be the class, since the term used for the class is of a different level of abstraction - a different Logical Type - from terms used for members. A1though in formal logic there is an attempt to maintain this discontinuity between a class and its members, we the maintalis discontinuit is continually and inevitably breached, and that a priori we must expect a pathology to occur in the human organism when certain formal patterns of the breaching occur...."1

As this quotation indicates, certain of the problems of modern logic

${ }^{1}$ Gregory Bateson, Don D. Jackson, Jay Haley, and John Veakland, "Toward a Theory of Schizophrenia", Behavioral Science, 1 (Oct., 1956). have captured the attention of the communicational psychologists. 2 One such problem arises out of the capacity of certain propositions to refer to themselves. The self-referential feature of an assertion like "I always $7 \mathrm{ie}$ " has been seen to reside at the heart of the logical paradoxes. If I am indeed lying, what I said cannot be true, and as I say I always lie I must be speaking the truth. If I am speaking the truth, then what I said must be true, and as I said I was 7ying, I must be 1ying. Each part of our alternative turns out to be self-contradictory; we have a formal inconsistency.

The psychologists have made a respectable case for adapting an expanded, modified version of the notion of self-reference to a totally different area of linguistic study. It must be kept in mind that they are working not with formal systems, but with the hurly-burly of actual interpersonal interchange. They require a notion of language which, while including syntactical and semantical features, must extend to encompass even non-verbal communications: gestures, facial expressions, tones of voice, posture, and social context. Thus they do not claim strict parallelism between their analyses and Russell's, but oniy that the latter's work has inspired insightful analogies.

The psychologists show some preference for the term "self-qualifying" ("self-qualification") as the counterpart of "self-referential." A common case of self-qualifying communications are those wherein the tone of voice operates on the linguistic aspect of the message. A says to $B$, "You're a splendid fellow", either in a tone of derision or in one of enthusiastic approval. It is as if $B$ receives two messages, the iinguistic claim, and another which can either disqualify or confirm it.

It may be that all interpersonal messages have this self-qualifying feature, a sort of subscript which signals "I mean what I say", or "I don't mean what I say". These qualifiers can be enormously subtle and intricate. Watzlawick ${ }^{3}$ relates that when Freud was attempting to leave Austria the Nazi authorities promised him an exit visa if he would sign a statement claiming he had been "... treated by the German authorities and particularly by the Gestapo with all the respect and consideration due to my scientific reputation...." Freud agreed to sign as long as he might add one further sentence which read, "I can heartily recommend the Gestapo to anyone". The effect of this addition was to disqualify

${ }^{2}$ The investigators 1 shall refer to here as communicational psychologists, or simply psychologists, may officially be employed as anthropologists, communication analysts, therapists, psychiatrists or psychologists.

${ }^{3}$ Paul Watzlawick, Janet Helmick Beavin, and Don D. Jackson, Pragmatics of Human Communication, A Study of Interactional Patterns, Pathologies, and Paradoxes. (New York: Norton, 1967), p. 207. 
the entire statement, and it could do so because of the special historical context which was indeed part of the communication. Viewed as a whole, the communication was now self-invalidating.

From this view of multifaceted communications which qualify themselves, it is an easy passage to the conceptual picture of levels of communication. Following the logician's distinction between an object-Tanguage and a meta-language, the psychologists find it useful to discuss interpersonal communication in terms of messages and messages about messages. When an individual qualifies his own 1 inguistic messages, say by an artificial laugh, a playful jab in the ribs, these are just as much communicative acts as the linguistic message they classify. And the most convenient way to regard these communicative acts is as messages about the linguistic message - a flasher which signals: "See this as sarcasm", or "See this as a joke". Now in the formulation of logical theory great effort is made by the participants to be explicit and clear as to which level an assertion belongs. But the usual situation in on-going interpersonal communication is that the speaker is himself unaware of the dual nature of his messages, and hence equally oblivious to the problems this poses for his listener. The interpersonal situation is further complicated by the fact that not only do speakers send second-level qualifications about their own messages, but they constantly comment on each other's communication, aga in without it being apparent to either party that this is occurring.

Consider the case of a couple who have had a bitter quarrel ostensibly because the husband, without consulting his wife, invited a mutual friend to stay at their home while in the area. Upon discussion each agreed it was natural to invite the friend to their home, yet somehow a deep disagreement was present.

What the psychologists claim is that, as long as one supposes there is only one level to the husband's message that he had invited the friend to their home, no clarification of their disagreement seems possible. But if we see in the husband's message the additional claim, provided by the circumstances surrounding its delivery, that he has a right to make unilaterally jointly binding decisions, a source of the difficulty is revealed. It is not the decision that is at issue, but who has the right to make the decision.

This may be made more explicit by conceiving the situation as governed by rules and meta-rules. The husband has proceeded as though there was the object-level rule, I have a right to invite home a mutual friend without consulting you. As they agree on the implementation of this rule in this case it is reasonable to suppose the wife's real question, and the nub of their conflict, is "By what (meta) rule do rules like that become operative in our relation?" Broadly phrased, the husband's implicit (meta) rule is, I can formulate and act upon unizateral miles in this relation; this is no doubt itself a unilateral rule, but of a higher level. The relevant bone of contention is not over the rules by which the couple operate, but over the rules affecting how their operating rules are introduced or established.

Russell proposed a hierarchy of languages as a vay out of the paradoxes. The psychologists see this procedure as suggestive of a way out of an analogical set of pragmatic paradoxes frequently called double binds. A double bind requires an interpersonal context wherein a message passes from $A$ to $B$ which both makes a claim and also affirms something about about that claim which is incongruent with it. Not only are $A$ and $B$ unaware of this complexity in their communication, but this communication is itself part of a powerful emotional bond of great importance to each of them. A peculiarity of the emotional tie is that it prevents $B$ from escaping from the net cast about him by A's messages. He cannot discuss these messages or physically remove himself from $A$. The emotional bond usually even disguises from $B$ that anything might be irregular about the messages he receives from $A$.

Consider the position of a youngster whose parents, because they believe him to be too dependent on them, sharply say "Don't be so obedient!" To obey this injunction he must disobey it. And for him to disobey it commits him to continue the obedient behaviour which prompted the injuction. He feels caught and vulnerable. To the uninvolved outsider escape may seem easy, but the youngster's dependency on his parents forces on him the view of his situation as an exclusive, exhausting and hopeless either-or.

There can be no asceptic ${ }^{4}$ way out of the pragmatic paradoxes such as Russell proposed for the logical paradoxes. Nonetheless the psychologists believe that in the theory of types Russell implicitly showed a necessary step to be taken by the captives of the double bind. Both kinds of paradox arise from a confusion of communicational levels, and the recognition of this confusion and its source is indispensable to their dissolution. Participants in a double bind must Tearn to communicate about how they communicate. No doubt more than logical skills are required, for a distinguishing feature which gives added complication to the pragmatic paradoxes is the degree to which they are laced through with our deepest feelings. But we may suppose Russell would have been pleased to learn his work had suggested a method of coming to terms with those feelings.

The first writer to see in human interaction analogs to Russell's theory of types was Gregory Bateson. In Communication, the Social Matrix

${ }^{4}$ [Sic. American readers may recognize this word sooner if it is spelled "askeptic". - Ed.] 
of Psychiatry ${ }^{5}$ Bateson reviews the relevance of Russell's paradox to psychiatry. This theme is more incisively developed in the important paper of 1956 quoted at the beginning of this essay. Russell is acknowledged by Jay Haley in an article, "Observation of the Family of the Schizophrenic", ${ }^{6}$ and in his book Strategies of Psychothercphy. ${ }^{7}$ In his book Sweet Madness, William F. Fry discusses Russell's paradox as part of a background for an analys is of humor. ${ }^{8}$ An excellent treatment of the ideas I outlined above is in the previously cited Pragmatics of Human Communication. In this book Russell is acknowledged not less than five times.

Expectedly, there are peer evaluations of the psychologists' employment of Russell's ideas, for instance, by Elliot G. Mishler and Nancy E. Waxler in their article, "Family Interaction Processes and Schizophrenia". 9 These authors initiate important innovations in the analysis of pragmatic meta-communication in their book Interaction in Families. 10 This is also true of the book Interpersonal Perception by R.D. Laing, H. Phillipson, and A.R. Lee. ${ }^{11}$ Laing has expressed some hesitancy about what he may regard as rather casual references on the part of some researchers to Russell's theory. He writes: "... they try to develop [their] formutation in terms of Logical Types. But it is doubtful if the Logical Type theory they employ is any longer viable."12 Nonetheless Laing makes brilliant use of the distinction between rules and meta-rules in Part II of his the Politics of the Family. ${ }^{13}$ His sometime collaborator, David Cooper, voices similar doubts about the psychological relevance of Russell's Theory of Types in Psychiatry and Anti-Psychiatry. ${ }^{14}$

Coming from a slightly different direction is Thomas S. Szaz who in The Myth of Mental IIIness ${ }^{15}$ refers to Russell in ten places, but particularly in chapter 16 in connection with his game model of human

${ }^{5}$ By Jurgen Ruesch and Gregory Bateson (New York: Norton, 1951). See pp. 195-6.

${ }^{6}$ American J. of Orthopsychiatry, 30 (July 1960)

${ }^{7}$ (New York: Grune and Stratton, 1963), p. 17.

8 (Palo Alto: Pacific Books, 1963), pp. 120-4.

9Merrizl-Palmer Quarterly of Behavior and Development, 2 (Oct. 1965).

10 New York: Wiley and Sons, 1968.

11 New York: Springer, 1966.

12The Self and Others (London: Tavistock Publications, 1961), pp. 140-1.

13 London: Tavistock Publications, 1971.

14 (London: Tavistock Publications, 1967), pp. 43-5.

${ }^{15} \mathrm{New}$ York: Harper and Row, 1961. behaviour. And finally (for the time being) Gregory Bateson, in his recent Steps to an Ecology of Mind, 16 indicates his continued high estimate of Russell's importance to his work.

How would Russell have viewed this rather surprising extension of his ideas? Surely he would have been intrigued, even if somewhat wary that the analogs between $\log i c$ and pragmatics might be overworked. And in so far as the outcome could contribute to our understanding of ourseives and others he certainly would have welcomed it as further vindication of his belief that philosophy can make a practical difference to how we live.

Department of Philosophy California State University (Fresno)

${ }^{16}$ San Francisco: Chandler, 1972 